\title{
A Proteção Contratual Do Consumidor E A Lei No 14.046/2020
}

\author{
Marcos Ehrhardt Júnior * \\ Universidade Federal de Alagoas, Programa de Pós-Graduação em Direito, Maceió-AL, Brasil. \\ iD http://orcid.org/oooo-0003-1371-5921 \\ Eduardo Henrique Costa ** \\ Universidade Federal de Alagoas, Programa de Pós-Graduação em Direito, Maceió-AL, Brasil. \\ iD https://orcid.org/0000-0002-2791-465X \\ Natália Tenório Fireman Camelo *** \\ Universidade Federal de Alagoas, Programa de Pós-Graduação em Direito, Maceió-AL, Brasil.
} iD https://orcid.org/0000-0001-8367-7436

Resumo: O artigo examina a Lei $\mathrm{n}^{0} 14.046 / 2020$, que trata do cancelamento, do reembolso e da responsabilidade civil de serviços ligados à indústria do turismo e do entretenimento, e as suas repercussões no direito do consumidor, na perspectiva do diálogo de fontes com a Constituição Federal e o Código de Defesa do Consumidor. O objetivo é investigar se o tratamento conferido pela referida lei respeita o núcleo normativo do microssistema de proteção ao consumidor, mormente o de equilíbrio dessas relações contratuais. A pesquisa foi realizada a partir do método científico dedutivo de revisão bibliográfica e documental em doutrina e em legislação nacional e estrangeira. Constatou-se que a legislação analisada traz retrocesso a conquistas sociais nas relações privadas, alcançadas constitucionalmente, como a proteção do vulnerável em condições de desequilíbrio negocial. A vedação, a priori, de danos extrapatrimoniais é uma clara demonstração da assimetria do diploma legal com o sistema de proteção ao consumidor e da reparação integral do dano. Por fim, verificou-se que as singularidades de cada conflito contratual, e eventual comportamento desleal, não devem ser desprezados com a limitação imposta pela norma quanto à responsabilidade do fornecedor, necessitando de aferição casuística pelo Poder Judiciário.

Palavras-chave: Pandemia. Direito do Consumidor. Contratos de consumo. Responsabilidade Civil.

\footnotetext{
* Doutor pela Universidade Federal de Pernambuco (UFPE). Professor de Direito Civil da UFAL e Professor de Direito Civil e Direito do Consumidor do Centro Universitário CESMAC. Editor da Revista Fórum de Direito Civil (RFDC). Diretor Nordeste do Instituto Brasileiro de Direito Civil (IBDCIVIL). Email: contato@marcosehrhardt.com.br

** Mestrando em Direito Público pela Universidade Federal de Alagoas (UFAL). Professor de Direito do Consumidor do Centro Universitário CESMAC. E-mail: eduardo@eduardocosta.adv.br

*** Mestranda em Direito Público pela Universidade Federal de Alagoas. Professora do Centro Universitário Mario Pontes Jucá - UMJ. E-mail: natalia@frlnadvogados.com.br
}

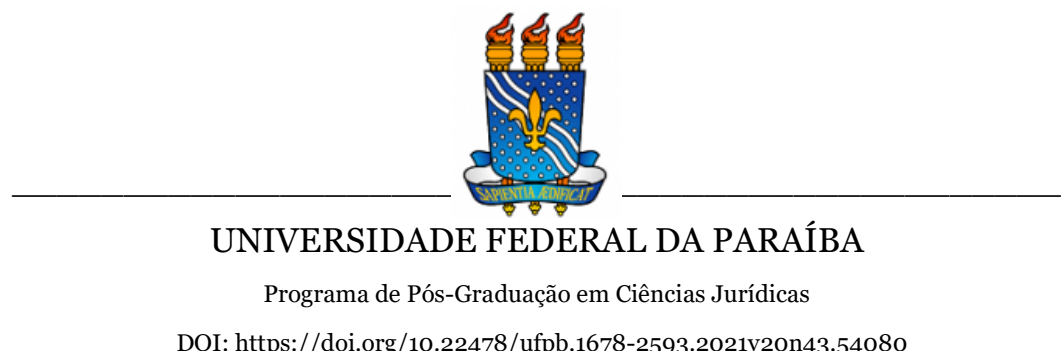

DOI: https://doi.org/10.22478/ufpb.1678-2593.2021v20n43.54080 


\title{
A Proteção Contratual Do Consumidor E A Lei No 14.046/2020
}

\author{
Marcos Ehrhardt Júnior
}

Eduardo Henrique Costa

Natália Tenório Fireman Camelo

\section{INTRODUÇÃO}

Os impactos da pandemia do coronavírus repercutiram em todas as atividades econômicas, com maior ou com menor abrangência, de acordo com as peculiaridades na sua execução ou no fornecimento. A indústria do turismo e a do entretenimento figuram entre aquelas mais afetadas, pelo caráter presencial e pela atual impossibilidade de aglomerações, que mesmo diante das medidas de relaxamento do isolamento social, ainda não são amplamente recomendadas pelos especialistas em saúde pública.

Diante da emergencialidade do momento e da constatação de que essas serão atividades econômicas que tardarão a retomar o seu funcionamento pleno, foi publicada a Lei ${ }^{0}$ 14.046/2020 ${ }^{1}$, em 25 de agosto de 2020, a fim de regular o cancelamento de serviços, de reservas e de eventos dos setores de turismo e de cultura. A norma busca reequilibrar tais relações, assim como ocorreu com o setor de aviação civil por meio da Lei no ${ }^{0}$ 14.034/2020.

${ }^{1}$ O tema foi tratado inicialmente pela Medida Provisória (MPV) $n^{0} 948 / 2020$, editada em 08 de abril de 2020, e, a partir do dia 25 de agosto de 2020, foi convertida na Lei ${ }^{0} 14.046 / 2020$. 
As medidas que visam proteger as empresas, contrabalanceando as normas de proteção ao consumidor, têm sido objeto de severas críticas pela modificação substancial encetada pelo regime especial instituído em relação ao regramento ordinário de tais relações negociais. A Lei $n^{0}$ 14.046/2020 altera significativamente as relações contratuais de consumo diante da previsão de dispensa de reembolso em caso de prestação posterior do serviço ou da conversão em crédito para o consumidor, além de criar regra excepcional, de redação bastante trincada, que parece indicar a impossibilidade de reparação civil decorrente da não prestação de serviços no período pandêmico.

A partir de uma revisão bibliográfica sobre o tema, o artigo investiga se as disposições da Lei $n^{0}$ 14.046/2020 flexibilizam os direitos dos consumidores a ponto de manter o equilíbrio, a boa-fé e a solidariedade necessários aos contratos de consumo. A investigação prossegue avaliando se, diante da pluralidade de fontes normativas e do necessário diálogo das fontes, há compatibilidade desse regramento com a defesa do consumidor.

\section{A PANDEMIA DO CORONAVÍRUS E A NORMALIDADE DA EXCEÇÃO}

Em 20 de março de 2020, foi declarado estado de calamidade pública no Brasil por meio da edição do Decreto Legislativo $\mathrm{n}^{\circ}$ 6, em consonância com a Portaria $n^{0}$ 188, de 3 de fevereiro de 2020, do Ministério da Saúde, reconhecendo a pandemia decorrente da infecção humana pelo novo coronavírus como uma situação de emergência de saúde pública de importância internacional ${ }^{2}$. A necessária agilidade

2 Neste sentido, a Lei $n^{0}$ 14.010/2020, que dispõe sobre o Regime Jurídico Emergencial e Transitório das relações jurídicas de Direito Privado (RJET) para o período da pandemia do coronavírus (Covid-19), prescreve, em seu art. $1^{\mathrm{O}}$, que o dia 
para contenção da doença exigiu a adoção de ações urgentes por parte dos governos. No âmbito do Poder Executivo Federal, enxergou-se a emergência sanitária como hipótese de relevância e urgência nacional, admitida pelo art. 62 da Constituição Federal, que autoriza a edição de medidas provisórias.

Nesse contexto, em abril de 2020, 26 instrumentos excepcionais dotados de força imediata de lei foram editados, entre eles a MPV nº 948/2020, que dispôs sobre o cancelamento de serviços, de reservas e de eventos dos setores de turismo e de cultura, com o evidente propósito de regular de forma transitória os contratos de consumo advindos desses setores, que tiveram suas atividades abruptamente interrompidas pelos efeitos da pandemia. Posteriormente, a aludida medida provisória foi objeto de conversão legal com a publicação da Lei $n^{0} 14.046 / 2020$, sob a qual se debruça a presente análise.

A legitimidade e a adequação das regulações excepcionais têm sido questionadas, pois na pretensão de controlar o caos econômico provocado pelos efeitos da pandemia, assumem a indisfarçável opção política de proteger o mercado, em completo detrimento dos mais vulneráveis, que o texto constitucional sempre primou por proteger.

Seria o argumento da imprevisibilidade da pandemia suficiente para justificar a adoção de medidas excepcionais que violam garantias constitucionais e causam um retrocesso às árduas conquistas do sistema jurídico brasileiro?

Neste particular, é oportuno reproduzir o questionamento de Rodotá (2003, p. 201): “pode sobreviver o direito em um mundo que parece dominado pelas leis férreas da economia e pela potência cega da técnica, em que a lógica da força quer cancelar as regras jurídicas e as grandes constituições da modernidade jurídica?”.

Tal qual a pandemia da cegueira branca, apresentada na obra ensaio sobre a cegueira de José Saramago, a transparência da 
pandemia do coronavírus criou uma claridade que cega, que impede de enxergar com exatidão que, não obstante a urgência das dificuldades apresentadas, não se deve perder de vista a evidência de que as respostas para lidar com essa crise sanitária estão no próprio ordenamento, na dignidade humana, na natureza normativa da Constituição e na dogmática jurídica, como adiante será observado.

\section{AS DISPOSIÇÕES DA LEI No 14.046/2020}

A Lei $\mathrm{n}^{0}$ 14.046/2020 disciplina os contratos de consumo vinculados à indústria do turismo e do entretenimento. Em linhas gerais, o referido diploma legislativo limita de forma genérica a autodeterminação contratual dos consumidores e preestabelece um modelo de responsabilidade civil que contraria o direito à reparação integral, ao retirar da apreciação do magistrado a possibilidade de indenização por dano extrapatrimonial.

Segundo a citada norma, serão regidas as relações travadas com prestadores de serviços turísticos e com sociedades empresárias elencadas no art. 21 da lei $\mathrm{n}^{0} 11.771 / 08$, tais como meios de hospedagem, agências de turismo, transportadoras turísticas, organizadoras de eventos, parques temáticos e acampamentos turísticos, bem como cinemas, teatros e plataformas digitais de vendas de ingressos pela internet.

Note-se que não está abrangindo o transporte aéreo, regido pela Lei $n^{0}$ 14.034/2020; tampouco há encaixe interpretativo que regule os sites que agregram em sua plataforma um combo de serviços (pacote aéreo, reserva de hotel e ingressos). Esta grave lacuna também não restou preenchida pelo diploma legal afeto ao transporte aéreo.

$\mathrm{O}$ art. $2^{\mathrm{O}}$ da Lei $\mathrm{n}^{0}$ 14.046/2020 reza que na hipótese de adiamento ou cancelamento de serviços, de reservas e de eventos, incluídos shows e espetáculos, o fornecedor do serviço não terá o dever 
de reembolso ao consumidor desde que: 1) seja assegurado o direito de remarcação, com respeito aos valores e as condições dos serviços originalmente contratados, a fim de evitar a locupletação do consumidor em condições superiores às adquiridas, a ser fruída no prazo de 18 (dezoito) meses após a cessação do estado de calamidade pública gerado pela pandemia; e, 2) a disponibilização de crédito ou abatimento na compra de outros serviços, cuja fruição fica limitada a 12 (doze) meses após o fim da pandemia.

Ainda determina que o referido direito de escolha do consumidor seja exercido prontamente a partir do dia $1^{\circ}$ de janeiro de 2020 até o prazo de: $i$ ) 120 (cento e vinte) dias, que será contado da comunicação do adiamento ou do cancelamento dos serviços; ou, ii) 30 (trinta) dias antes da realização do evento, o que acontecer primeiro, sem a incidência de qualquer encargo ou acréscimo decorrente dessa operação. Se não houver manifestação do consumidor, o referido prazo de escolha poderá ser excepcionalmente restituído em caso de internação do consumidor, aos seus herdeiros ou sucessores em caso de falecimento, ou ainda em virtude de hipótese de força maior.

Decorrido o prazo de escolha, a norma não veda a exigibilidade de cobrança de taxa ou multa pela escolha intempestiva, nem menciona pormenores sobre a liberdade contratual para a aplicação eventual de tais encargos. Todavia, o referido prazo de escolha poderá ser excepcionalmente restituído em caso em que não houver a manifestação do consumidor em razão de sua internação, de transmissão de direito aos seus herdeiros ou sucessores em caso de falecimento, ou ainda em virtude de hipótese de força maior.

Importante notar que a possibilidade de restituição foi abordada no texto legal no art. $2^{\circ}, \S 6^{\circ}$, mas de forma restrita, isto é, somente se as opções previstas não forem passíveis de cumprimento, é que o fornecedor terá a obrigação de reembolsar a quantia paga pelo consumidor, com correção monetária aferida pelo índice do IPCA, no prazo de 12 meses, contados da superação oficial da pandemia pelo 
Estado. O legislador fez um importante acréscimo no texto original da medida provisória 948/2020, ao prever a dedução de eventuais valores que se refiram a serviços já prestados de agenciamento ou de intermediação, a exemplo da taxa de conveniência e/ou de entrega, tanto para uso ou para abatimento na compra de novos serviços, quanto na hipótese de restituição.

Em razão da incerteza quanto à cessação dos efeitos da emergência de saúde pública, nos casos de escolha pela remarcação, as disposições já vistas se aplicam, inclusive, às hipóteses em que o serviço, a reserva ou o evento adiado necessitar de novo adiamento. Bem assim, tal previsão também se aplicará aos novos eventos lançados, no decorrer do período de emergência em saúde pública, e que não puderem ser realizados por esse motivo.

Por fim, o art. $5^{\circ}$ cuida da responsabilidade civil dos casos regidos pela lei com uma redação, no mínimo, confusa. A norma preconiza que todas as relações de consumo por ela tuteladas são hipóteses de caso fortuito ou força maior e não autorizam a reparação indenizatória por danos morais, nem a aplicação de multas ou outras penalidades aplicáveis pelo Estado na esfera administrativa. Ressalvam-se desta regra geral os casos de dedução dos valores referentes a serviços de agenciamento ou de intermediação, contanto que caracterizada a má-fé do prestador de serviço ou da sociedade empresária3.

3 Eis a íntegra do referido dispositivo: "Art. $5^{\circ}$. Eventuais cancelamentos ou adiamentos dos contratos de natureza consumerista regidos por esta Lei caracterizam hipótese de caso fortuito ou de força maior, e não são cabíveis reparação por danos morais, aplicação de multas ou imposição das penalidades previstas no art. 56 da Lei $\mathrm{n}^{0}$ 8.078, de 11 de setembro de 1990 , ressalvadas as situações previstas no $\S 7^{\circ}$ do art. $2^{\circ}$ e no $\S 1^{\circ}$ do art. $4^{\circ}$ desta Lei, desde que caracterizada má-fé do prestador de serviço ou da sociedade empresária.” 


\section{PLURALIDADE DE FONTES E INTERPRETAÇÃO DO DIREITO DO CONSUMIDOR}

A excepcionalidade ocasionada pela Covid-19 demanda a adoção de algumas medidas, inclusive no âmbito jurídico, que se afastam do cenário de normalidade das relações entre particulares. Não se perca de vista que a proteção ao consumidor não é diretriz isolada, pois como a Constituição assenta, em seu art. 170, que a ordem econômica deve ser articulada a partir de diversos princípios, como a proteção à livre concorrência, a defesa do consumidor, a valorização do trabalho humano e entre outros. Sem uma hierarquia previamente definida, tais princípios devem ser conjugados de acordo com os objetivos constitucionais, que são consubstanciados na própria finalidade da ordem econômica, a saber, assegurar a todos uma existência digna, conforme os ditames da justiça social (CUNHA JUNIOR, 2020, p. 1.269).

Nesse sentido, Eros Grau (2018, p. 161) sustenta que a Constituição não se interpreta em pedaços, de modo que qualquer texto normativo impõe ao intérprete o percurso que se projeta a partir do texto constitucional. Com efeito, uma das formas de efetivamente proteger o consumidor é justamente lhe assegurar um mercado diversificado e não concentrado, afinal a livre concorrência preconizada na Constituição federal de 1988 é um processo comportamental competitivo, que também é forma de tutela do consumidor, porquanto a competividade induz uma distribuição de recursos a mais baixo preço (FERRAZ JUNIOR, 1989).

Miragem (2019) aduz que o conceito de bem-estar do consumidor está relacionado a vantagens obtidas, como: 1) melhores preços, 2) melhor qualidade, 3) maior diversidade de oferta. Para ele, “é a compatibilização de interesses legítimos de consumidores entre si e dos fornecedores e demais agentes econômicos que permitem 
identificar in concreto o bem-estar do consumidor" (MIRAGEM, 2019, p. 101).

A necessidade de contraponto entre os interesses de consumidores e de fornecedores foi positivada como um dos vetores da Política Nacional das Relações de Consumo, tendo o Código de Defesa do Consumidor (CDC) previsto expressamente o dever de harmonização e compatibilização dos interesses dos participantes das relações de consumo a partir da boa-fé objetiva e do equilíbrio contratual.

Ao buscar proteger o mercado de eventos e de atividades turísticas, o tratamento conferido pela Lei $n^{0}$ 14.046/2020 novamente lança novamente lança luzes em um dos problemas do direito privado na contemporaneidade, que é a pluralidade de fontes normativas e a necessidade de coexistência sistemática entre elas, no que a doutrina pátria convencionou denominar de diálogo de fontes.

A edição de leis emergentes para dirimir conflitos nos contratos privados em virtude da pandemia é medida bem-vinda, dada a agudeza da emergência sanitária e do colapso iminente da economia, mas, ao mesmo tempo, reforça a discussão sobre o alcance de suas disposições em relação ao núcleo normativo da proteção ao consumidor. Dito de outro modo: estaria a lei em análise no mesmo diapasão de todo o sistema jurídico protetivo das relações de consumo, que tem como marco zero os valores assegurados na Constituição Federal?

Na perspectiva do Superior Tribunal de Justiça, a tutela prioritária da pessoa humana nas relações de consumo e a necessária compatibilização da pluralidade de fontes normativas advém da legalidade constitucional, como fundamento de unidade do ordenamento. Essa tutela prioritária e a obrigatória compatibilização das fontes se origina na proteção da dignidade humana, especialmente quando em situação particular de vulnerabilidade, e privilegiando valores não patrimoniais. (OLIVA; TEPEDINO, 2020, p. 49)

Para a unificação do sistema jurídico proposta pela Constituição Federal, foi desenvolvida a metodologia de constitucionalização das 
relações privadas, em que todo o Direito, inclusive o privado, deve ser interpretado à luz da Constituição. Imprescindível, portanto, "que o intérprete promova a conexão axiológica entre o corpo codificado e a Constituição da República, que define os valores e princípios fundantes da ordem pública" (OLIVA; TEPEDINO, 2020, p. 52). Este processo hermenêutico busca assegurar que "cada interpretação é um microcosmo da imensa tarefa de realização de uma sociedade livre, justa e solidária" (LÔBO, 2019, p. 59).

Logo, a divisão estanque entre direito público e direito privado, em que o Código Civil atuava como diploma legal de vértice, foi suplantada pela necessidade de uma interpretação atenta à unidade da Constituição e, em consequência, do próprio ordenamento jurídico que dela colhe o seu substrato de validade.

Não fosse isso o bastante, a produção legislativa tem se tornado, cada vez mais, setorial e especializada em razão da complexidade que as relações sociais têm assumido, privilegiando a criação de pequenos estatutos temáticos. Há quem anote, como Natalino Irti (1999, p. 40), que o Código Civil sofre uma inversão de função, passando de lei geral para lei residual, já que a eclosão de leis especiais passa a assumir classes inteiras de relacionamentos, conferindo tratamento jurídico próprio e provocando o surgimento de novos princípios em leis especiais.

A proteção ao consumidor no Brasil é direito humano social e econômico positivado na Constituição Brasileira, que assegura tutela especial enquanto agente econômico mais vulnerável no mercado globalizado (MARQUES, 2004. p. 17). E o próprio Código de Defesa do Consumidor (CDC), que é a materialização desse substrato constitucional, admite de modo expresso, em seu art. $7^{\circ}$, a pluralidade de fontes para a regência dos interesses dos consumidores.

No entanto, importante anotar que a existência de fontes normativas específicas sobre determinada matéria de consumo não afasta, por si só a incidência do CDC, pois, enquanto microssistema, conforma toda a produção normativa de consumo, de modo que as 
normas especiais sobre relações de consumo não devem ferir o núcleo do Código de Defesa do Consumidor. É sob esta ótica que deve ser analisada a intensidade da intervenção do Estado nos contratos de consumo por meio da Lei ${ }^{0}$ 14.046/2020.

\section{REPERCUSSÕES CONTRATUAIS DA LEI No 14.046/2020}

O Código de Defesa do Consumidor estabelece um claro diálogo de fontes com o Código Civil no campo contratual, mas possui pressupostos interpretativos próprios, adaptados à sua finalidade de reger relações essencialmete díspares, marcadas pelo traço da vulnerabilidade.

Ao estabelecer a morfologia dos contratos de consumo em busca de um equíbrio efetivo, o CDC proíbe a existência de cláusulas que subtraiam ao consumidor a opção de reembolso da quantia já paga (art. 51, II); que coloquem o consumidor em desvantagem exagerada (art. 51, IV); que deixem ao fornecedor a opção de concluir ou não o contrato, embora obrigando o consumidor (art. 51, IX); que autorizem o fornecedor a cancelar o contrato unilateralmente, sem que igual direito seja conferido ao consumidor (art. 51, XI); ou que simplesmente estejam em desacordo com o sistema de proteção ao consumidor (art. 51, XV).

Se os contratos de consumo não podem ser concebidos em desacordo com o sistema de proteção ao consumidor, tampouco o poderá a produção legislativa, dada a recondução axiológica da proteção ao consumidor à Constituição Federal, como já delineado no tópico antecedente.

É fato que o modelo vigente de revisão dos contratos de consumo sempre foi concebido a partir de uma presunção absoluta de vulnerabilidade do consumidor em relação ao fornecedor. Todavia, o cenário atípico gerado pela pandemia fragilizou ambos os polos da relação jurídica. 
Segundo Mucelin e D’Aquino, na esteira da Covid-19, a Organização para a Cooperação e Desenvolvimento Econômico (OCDE) divulgou uma previsão de prejuízo de US\$ 50 bilhões para a indústria do turismo. No início de março de 2020, a Associação Internacional do Setor Aéreo calculava uma perda de receita de até US \$ 113 bilhões em razão da pandemia, número que deve crescer depois da divulgação das medidas proibitivas pelo governo norteamericano (D'AQUINO; MUCELIN, 2020, p. 9).

Como destaca Schreiber (2020, p.3), cabe ao Direito fornecer à sociedade instrumentos jurídicos "que preservem, tanto quanto possível, os direitos fundamentais dos cidadãos brasileiros e as bases econômicas necessárias para que esses direitos sejam exercidos em sua máxima intensidade”, a fim de evitar a utilização oportunista dos instrumentos contratuais. As relações contratuais devem ser reavaliadas à luz da boa-fé e do equilíbrio, que são vetores de mão dupla, servindo tanto para aferir concretamente a posição de consumidores quanto de fornecedores, como alinhavado na política nacional de defesa do consumidor.

Essa constatação, mais uma vez, remete ao paradoxo do liberalismo: necessitar da intervenção do Estado Social. Em momentos de estabilidade, o livre mercado (e o seu eficientismo) busca afastar tanto quanto possível a intervenção do Estado na atividade econômica, mas se socorre justamente da tutela estatal, seja pela instituição de auxílios econômicos, ou seja, pela adoção de medidas legislativas, as quais regulam favoravelmente seus interesses.

O New Deal, plano de recuperação econômica operado pelo governo Roosevelt nos Estados Unidos, na década de 30, após a crise de 1929, e as medidas adotadas, em escala global, durante a crise de 2008, cujo epicentro foi o colapso de crédito do sistema imobiliário americano, retratam com clareza esse movimento. Com ou sem culpa, o mercado socorre-se do Estado para equilibrar sua situação diante de uma imprevisão ou de um problema incontornável. O reflexo dessas injunções na esfera contratual pode ser assim demonstrado: 
No campo dos contratos, entretanto, um novo debate vem aflorando. Atualmente podemos claramente definir duas concepções opostas sobre este instituto: uma tradicional, focada no liberalismo econômico, que o enxerga como compromisso de interesses divergentes (antagônicos), e outra mais inclinada a entendê-lo como um ato de auxílio mútuo (colaboração) a partir de uma perspectiva solidarística. (EHRHARDT JUNIOR, 2008, p. 73)

Na quadra atual, há de se destacar o solidarismo contratual que, no dizer de Daniel Sarmento (2004, p. 338), "implica o reconhecimento de que, embora cada um de nós componha uma individualidade, irredutível ao todo, estamos também todos juntos, de alguma forma irmanados por um destino comum".

O solidarismo não ignora as posições e os interesses contrapostos das partes, mas corresponde a uma busca pela superação de modelo adversarial, pois o contrato implica efeitos existenciais e econômicos para todos os envolvidos e deve ser compreendido como "a obrigação imposta aos contratantes de colaboração mútua, sobretudo para melhor deslinde de relações cada vez mais complexas entre as pessoas" (EHRHARDT JUNIOR, 2008, p. 74).

Mas, qual seria o limite da solidariedade contratual em tempos de pandemia?

Embora a complexidade do tema não permita uma resposta singela e objetiva, Tartuce (2020, p. 8) defende enfaticamente a adoção de três vetores para a superação das dificuldades contratuais, quais sejam bom senso, boa-fé e solidariedade, nos seguintes termos:

Chegou o momento de as partes contratuais no Brasil deixarem de se tratar como adversários e passarem a se comportar como parceiros de verdade. Ao invés do confronto, é preciso agir com solidariedade. De nada adiantará uma disputa judicial por décadas, com contratos desfeitos e relações jurídicas extintas de forma definitiva. Bom senso, boa-fé e solidariedade (TARTUCE, 2020, p.8).

Pelas linhas transcritas acima, parece adequada a adoção de mecanismos que privilegiem o diálogo e a adaptação dos contratos à realidade singular das partes de um contrato. No entanto, pela assimetria típica dos contratos de consumo, tal orientação não teria o 
condão de evitar a judicialização maciça das relações negociais efetivadas antes da pandemia.

Buscando reduzir a insegurança jurídica sobre o tema enquanto o Poder Judiciário não estabelecesse seus standards interpretativos, veio a lume o diploma legal em comento para regular os setores abrangidos; a generalização de suas disposições suscita o questionamento inicial: há equilíbrio, boa-fé e solidariedade nas suas disposições em defesa do consumidor?

A variedade e a complexidade de serviços absolutamente distintos, mas tutelados identicamente pela Lei n 14.046/2020, trazem à tona a primeira crítica, entre as muitas possíveis, sobre os anacronismos e as omissões nela presentes: tratar desiguais como iguais.

As soluções contidas no art. $2^{\circ}$ do texto legal, já comentadas em tópico anterior, resolvem uniformemente relações singulares e de complexidade e de execução diferenciadas. O consumidor que adquiriu ingressos para uma sessão de cinema tem uma situação complementamente distinta de quem adquiriu um pacote de viagem para o exterior e por qualquer razão de foro íntimo não possua mais interesse na continuidade do negócio. Mas o tratamento dispensado na norma, repita-se, é o mesmo.

De acordo com o referido dispositivo, em suma: o fornecedor deve oferecer duas opções ao consumidor, que consistem: 1) no direito de remarcação; e, 2) na conversão em crédito ou abatimento no preço na contratação de outros serviços. A escolha do consumidor deve ser exercida, sem nenhum encargo, entre o dia $1^{\circ}$ de janeiro de 2020 até $o$ prazo de 120 (cento e vinte) dias, que será contado da comunicação do adiamento ou do cancelamento dos serviços, ou até o prazo de 30 (trinta) dias antes da realização do evento, o que ocorrer primeiro. Em caso de internação ou de força maior, o prazo de 120 (cento e vinte) dias é devolvido em favor do consumidor, ou de seus herdeiros ou sucessores, por motivo de falecimento. Oferecida a prestação futura do 
serviço, não haverá direito de reembolso, e quando existir, ficará condicionado ao prazo de até 12 meses após a cesssação da pandemia.

A proteção ao livre mercado é medida salutar para os interesses dos próprios consumidores, mas a lei extravagante não pondera adequadamente os interesses, conforme analisado a seguir.

Ausência de unidade no tratamento legislativo. A Lei Federal $\mathrm{n}^{0}$ 14.010/20, que trata do regime Jurídico Especial Transitório, mais conhecido como RJET, estabelece normas de regência das relações privadas em razão dos precalços gerados pela Covid-19. Malgrado as disposições sobre contratos do referido diploma legal tenham sido vetadas pela Presidência da República4, o seu texto original continha previsão expressa de que os contratos de consumo não sofreriam nenhuma restrição para a sua revisão em decorrência da pandemia. É dizer, mesmo reconhecida a excepcionalidade do momento, a vulnerabilidade do consumidor não poderia ser agravada pelo Estado justamente porque sua missão é o oposto disso.

É oportuno destacar que a Lei Federal $n^{0} 14.010 / 20$ nasceu do regular processo legislativo, com o auxilio de renomados especialistas em Direito Privado na elaboração de seu texto, enquanto a Lei $\mathrm{n}^{\mathrm{o}}$ 14.046/2020, aqui em análise, decorreu da conversão da Medida Provisória ${ }^{0}$ 948/2020, e, inobstante algumas inclusões das casas legislativas, é inegável que adveio de iniciativa do Poder Executivo. A diferença apontada no nível de intervenção estatal nos contratos de consumo, em ambos os diplomas, somente ressalta a vulnerabilidade política do consumidor, defendida por Paulo Dal Pai Moraes (2009, p. 164), que aduz:

Cada vez mais as discussões, principalmente as jurídicas, pendem para a proteção dos valores econômicos ao invés dos valores sociais, estabelecendo odiável hierarquia e aumentando a vulnerabilidade política que macula os consumidores, quando, em realidade, deveriam estar os sistemas mesclados para o atendimento das necessidades de todos os homens, e não somente de alguns.

\footnotetext{
4 No momento em que este artigo foi redigido, o veto presidencial ainda se encontrava sujeito à derrubada pelo Congresso Nacional, o que tornaria válidas as normas previstas no RJET sobre contratos civis, interempresariais e de consumo. 
Escasso prazo para o exercício do direito de escolha. $\mathrm{O}$ objetivo da norma é possibilitar aos empreeendores tempo adequado para reorganizar suas operações e, assim, futuramente cumprir com as obrigações contratuais. Todavia, a Lei ${ }^{0}{ }^{14.046 / 2020}$ determina que o consumidor opte pela remarcação ou conversão em crédito entre o dia $1^{\circ}$ de janeiro de 2020 e o prazo de 120 (cento e vinte) dias, que será contado da comunicação do adiamento ou do cancelamento dos serviços; ou até o prazo de 30 (trinta) dias antes da realização do evento, o que ocorrer primeiro. A norma autoriza que a escolha seja realizada posteriormente, mas com a incidência de encargos para a remarcação.

Diversamente da técnica adotada no RJET, que condiciona os prazos para o período após a cessação da pandemia, a referida lei impele o consumidor a exercer o direito de escolha prematuramente, mesmo que não se possa atualmente antever o futuro, vale dizer, a extensão da pandemia e dos seus impactos econômicos na vida pessoal de cada um, como eventual desemprego, perda de renda ou excessiva desvalorização cambial.

Limitação substancial do direito de escolha do consumidor e o desestímulo à adoção de soluções negociadas entre as partes. A norma do artigo $2^{\circ}$ da Lei $n^{0}$ 14.046/2020 parece ser inspirada na mesma técnica legislativa utilizada pelos art. 18 (direito de escolha pela não sanação do vício do produto no prazo) e art. 35 (descumprimento da oferta) do CDC, que lhe oferece um direito postetativo a ser exercido soberanamente entre as duas opções legais respectivamente apresentadas.

Não se oberva no mencionado art. $2^{\circ}$ um direito de escolha entre obrigações proporcionalmente satisfatórias para a tutela dos interesses do consumidor; este se vê compelido a prosseguir no contrato mesmo sem desejar a fruição futura do serviço. A norma confere como opções o reagendamento do serviço e a sua conversão em crédito, cuja fruição poderá ocorrer no prazo de 18 (dezoito) meses em caso de remarcação, ou de 12 (doze) meses para a disponibilização 
do crédito ou abatimento do seu valor para outro contrato com a mesma empresa, após a cessação da pandemia; limitando o direito ao reembolso à não execução futura do serviço. Portanto, diante da promessa de prestação do fornecedor, o consumidor não tem autonomia de vontade apta a discutir outra solução que lhe seja substancialmente satisfatória, o que, em parte, esvazia o dever de renegociar, imposto pelo solidarismo contratual.

Assim, não é exagero concluir que a preocupação com o fluxo de caixa das empresas e com o ambiente econômico em geral ignora a situação econômica dos consumidores, circunstância que antecede o desarranjo provocado pela pandemia, afinal empresas superendividadas contam com um regime legal de recuperação judicial, enquanto consumidores, na mesma situação, carecem de instrumentos normativos nesse sentido, malgrado as proposições legislativas em trâmite no Brasil.

\section{Ônus adicional decorrente da escolha de conversão em} crédito. A redação da medida provisória 948/2020 assegurava ao consumidor a escolha dentre o direito de rembolso, à remarcação do serviço ou outra solução negociada sem qualquer ônus adicional, exceto pela possibilidade de cobrança de multa pelo exercício de escolha fora do prazo legal. Ao se debruçar sobre o texto da M.P, o Congresso Nacional acrescentou mais um encargo a ser suportado pelo consumidor, que é o dever de dedução sobre o crédito de valores referentes a serviços de agenciamento e de intermediação já prestados, tais como taxa de conveniência e/ou de entrega.

A medida contida no $\S 7^{\circ}$ do art. $2^{\circ}$ representa um agravamento na condição contratual do consumidor ao impor uma diferenciação substancial entre as opções legais, induzindo o contratante vulnerável a preferir o reagendamento à conversão em crédito, dadas as consequências apresentadas. Além disso, a legalização da incidência da taxa de conveniência está na contramão dos parâmetros adotados recentemente pelo Superior Tribunal de Justiça, que no julgamento do Recurso Especial no 1.737.428/RS, realizado em 12/03/2019 considerou abusiva a cobrança de taxa de conveniência na venda de 
ingressos em meio virtual (internet). Nesse sentido, explicam Ehrhardt e Costa (2020, p. 529) que:

[...] a taxa de conveniencia é uma prática abusiva pela violação sistemtática de princípios e cláusulas abertas que regem a aplicação do direito privado na contemporaneidade. Na concepção do STJ, o desenho do negócio jurídico das empresas de bilheteria digital viola os padrões negociais da boa-fé objetiva.

Com efeito, a opção legislativa poderá sofrer contestação no Poder Judiciário, ocasionando desnecessária insegurança jurídica. A norma determina o oposto da ratio decidendi do precedente citado, que foi construído a partir de uma interpretação sistemática dos interesses envolvidos. Mas seu principal efeito é gerar um desequilibrio qualitativo e quantitativo nas opções postas para a escolha do consumidor, pois não há de fato um direito potestativo de escolha diante de opções assimétricas, que apelam em uma direção.

Ampliação excessiva do prazo de reembolso. A Lei $n^{0}$ 14.046/2020, além de condicionar o reembolso à escolha do fornecedor em não prestar o serviço contratado, concede-lhe um prazo de 12 meses, após o fim da pandemia, para reembolsar os valores pagos pelos consumidores, acrescidos de correção monetária. A necessidade de reorganização das empresas não pode importar em um grave desequilíbrio que beneficie apenas um dos sujeitos da relação de consumo, e justamente o polo mais forte.

A respeito desse prazo de reembolso, igualmente previsto na Lei $\mathrm{n}^{0}$ 14.034/2020 (que regula o transporte aéreo), comenta Tartuce (2020, p.6):

De todo modo, não se pode admitir, com essa solução, uma proteção exagerada de qualquer uma das partes para que, por exemplo, os valores sejam devolvidos somente após um longo período de tempo, fora da esperada razoabilidade. Assim, um prazo de doze meses para a devolução dos valores relativos às passagens áreas me parece algo excessivo.

Além de vedar a responsabilização dos fornecedores - tema tratado a seguir -, a proteção conferida pela Lei $n^{0} 14.046 / 2020$ aos fornecedores não se coaduna com o sistema de proteção ao 
consumidor vigente. Normas tão assimétricas com a tutela do consumidor, especialmente quando adotadas sem a realização de nenhum estudo técnico ou a demonstração de critérios objetivos para a fixação de tal prazo, de acordo com as injunções sociais, em vez de equilibrar as relações, em verdade, aprofundam a disparidade existente e desestimulam o diálogo entre as partes na construção de soluções consensuais.

\section{A TUTELA DA PERSONALIDADE E A IMPOSSIBILIDADE DE RESTRIÇÃO DE DANOS EXTRAPATRIMONIAIS}

Como demonstrado nos itens anteriores, não se pode abandonar os valores supremos que estão na base da Constituição, irradiados em todo o ordenamento, em prol de um esforço para salvaguardar o capital, que subverte a ordem social a fim de proteger o livre mercado. É preciso reconhecer na própria legislação, a ordem legal que emergiu espontaneamente como consenso moral da comunidade, como a única arma disponível para lidar com situações emergenciais ou em condições de evidente desequilíbrio (SCRUTON, 2015, p. 88-89).

O empenho para garantir a sustentabilidade do setor econômico não pode refletir um pensamento utilitarista, implicando um volver para a tradição patrimonialista, trajetória incompatível com os valores fundados na dignidade da pessoa humana. A "restauração da primazia da pessoa humana nas relações civis é condição primeira da adequação do direito aos fundamentos e valores constitucionais" (LÔBO, 2019, p. 64).

É fundamental sublinhar o entendimento de Rodotá (2012, p. 10), para quem a repersonalização das relações civis se desenvolve na constitucionalização da pessoa, que é o produto de uma marcha antropológica que parte do sujeito como proprietário e contratante, na 
direção do seu reconhecimento como pessoa, como indivíduo, lastreado na humanidade e na dignidade social, que não se submetem à lógica do mercado ou à razão pública.

Como exemplo de valores que não podem ser menosprezados, a defesa do consumidor expressa uma das garantias fundamentais previstas no art. $5^{\circ}$, XXXII, da CF, e como já visto, prestigiada mais de uma vez no texto da Magna Carta, em seu art. 170, V, constitui um princípio geral da atividade econômica.

Atendendo ao comando constitucional previsto no art. 48 do ADCT, a promulgação do Código do Consumidor objetivou reger o fornecimento de produtos e serviços no mercado de consumo, priorizando a proteção contratual do consumidor e a responsabilidade do fornecedor dos produtos e do prestador dos serviços ofertados (LÔBO, 2019, p. 25).

A defesa do consumidor sempre teve como função "reequilibrar as forças dos sujeitos da relação consumerista, diminuir a vulnerabilidade do consumidor e limitar as práticas nocivas do mercado" (THEODORO JUNIOR, 2017, p. 23). Não por acaso, os contratos de consumo, embora não se desvinculem dos valores adotados para os contratos de direito privado em geral, diferenciamse destes por buscar evitar os abusos provocados pelo fornecedor do bem ou pelo executor do serviço, entendidos como estamentos econômicos mais fortes (DELGADO, 1999, p. 56).

Dito de outro modo, nas relações de consumo, há uma clara assimetria que advém da posição de preponderância exercida pelo fornecedor, com mais poder nas decisões afetas ao curso ou cumprimento do contrato, e acaba desempenhando um papel dominante. Em razão deste desequilíbrio, a proteção dos interesses do consumidor vulnerável é medida que se impõe para limitar o poder do fornecedor mediante uma política de prevenção de danos, que somente é possível graças à intervenção legislativa do CDC na autonomia contratual privada (MIRAGEM, 2019, p. 114), alcançada ao assegurar um "direito de danos voltado ao consumidor, vedando 
práticas que tragam prejuízo (tanto patrimonial quanto extrapatrimonial) ao vulnerável”. (D’AQUINO; MUCELIN, 2020, p. 38-39)

Esta proteção do consumidor se relaciona com a proteção da dignidade da pessoa humana e, como tal, insere-se no estudo da tutela da personalidade. Schreiber (2014, p. 15), ao interpretar a proteção da personalidade e dos direitos fundamentais, com base na metodologia da constitucionalização das relações privadas, pontua que:

A maior parte dos direitos da personalidade mencionados no Código Civil brasileiro (imagem, honra, privacidade) encontra previsão expressa no art. $5^{\mathrm{o}}$ do texto constitucional. Mesmo os que não contam com previsão explícita nesse dispositivo são sempre referidos como consectários da dignidade humana, protegida no art. $1^{\mathrm{o}}$, III, da Constituição. Os direitos da personalidade são, portanto, direitos fundamentais.

No caso de ofensa à dimensão subjetiva da dignidade humana do consumidor, é cabível a reparação por danos morais. Maria Celina Bodin de Moraes (2003, p. 127) enxerga nesse raciocínio a evidência da tutela da personalidade, ao ponderar que "eis aí as razões pelas quais as hipóteses de dano moral são tão frequentes, porque a sua reparação está posta para a pessoa como um todo, sendo tutelado o valor da personalidade humana”.

Ocorre que, em sentido oposto ao ora apresentado, a Lei $n^{0}$ 14.046/2020, na pretensão de regular de forma transitória as relações de consumo e no intuito de evitar um colapso do setor do turismo e da cultura, praticamente eliminou a possibilidade de danos morais (art. $5^{\circ}$ ), enquadrando as relações de consumo por ela tuteladas como hipóteses de caso fortuito e força maior em patente violação do princípio constitucional da reparação integral dos danos.

O caso fortuito e a força maior estão regulados pelo art. 393 do Código Civil, no capítulo que trata sobre o inadimplemento das obrigações, com a seguinte redação:

Art. 393. O devedor não responde pelos prejuízos resultantes de caso fortuito ou força maior, se expressamente não se houver por eles responsabilizado. 
Parágrafo único. O caso fortuito ou de força maior verificase no fato necessário, cujos efeitos não era possível evitar ou impedir.

A norma extravagante enquadra os cancelamentos e adiamentos dos seus vínculos de consumo, de forma categórica, como situações que não ensejam a responsabilização do fornecedor, pois o "caso fortuito ou de força maior terá o condão de afastar o nexo de causalidade, liberando o indigitado responsável de qualquer tipo de dever indenizatório". (SILVA, 2020. p.222). E é preciso ressaltar que nem todas as impossibilidades imputáveis ao devedor se exoneram por conexão direta com o caso fortuito ou de força maior, mas, ao revés, são inclusive elas a causa do dever de indenizar eventuais danos que o credor sofra. (SILVA, 2020, p. 236-237)

Ao se afastar de forma peremptória, e quase que completamente, a possibilidade de se pleitear dano moral, incorre-se em grave erro, uma vez que o texto legal em análise parte de uma vedação a priori, deixando de excepcionar as hipóteses que envolvam eventuais comportamentos oportunistas e mercenários de fornecedores e prestadores, em prejuízo dos direitos de personalidade dos consumidores. Essa leniência no tratamento de fornecedores de um setor específico, sem justificativa alguma, certamente ressoará como um estímulo à adoção de comportamentos abusivos vedados pelo artigo 187 do Código Civil, que prestigia a observância da função social e da boa-fé nas relações entre particulares.

Até mesmo a ressalva prevista pela norma, ao excepcionar desta vedação os casos de má-fé quanto à dedução dos valores referentes a serviços de agenciamento ou de intermediação pelos prestadores de serviço ou sociedade empresária, reforça a ofensa ao sistema protetivo tão caro ao Código de Defesa do Consumidor de forma agravada por advir do próprio legislador, pois limitar a possibilidade de aferição de comportamento desleal, contrário a boa-fé contratual esperada, “um dos fins perseguidos pelo sistema, que é a lealdade, a honestidade, a probidade, a cooperação, a proteção da confiança nas relações de 
consumo" (ZANELLATO, 2020, p. 142) potencializa a fragilidade do consumidor ainda mais vulnerável com os efeitos da pandemia.

Para garantir a legalidade constitucional, os conflitos decorrentes das relações tuteladas pela Lei $n^{0}$ 14.046/2020 necessitam ser resolvidos pelo intérprete, pois na contemporaneidade, o panorama brasileiro impõe que cabe a ele a integração do sistema jurídico (OLIVA; TEPEDINO, 2018, p. 52). E nesse exercício integrativo, é imperioso reconhecer que a vedação do dano moral, salvo restrita exceção, ofende a dignidade humana do consumidor, cuja vulnerabilidade já inflamada pelo fenômeno pandêmico, cresceu ainda mais, colimada pela intervenção estatal indevida.

Portanto, como principal intérprete, caberá ao Poder Judiciário apreciar a constitucionalidade da vedação de se buscar reparação por danos morais, atualmente descrita no diploma legal em comento, que flagrantemente viola o princípio da isonomia, por criar hipótese de exclusão sem nenhum elemento necessário ou adequado que corrobore a necessidade de tratamento distinto aos envolvidos, não havendo respaldo para se blindar da apreciação do Judiciário ofensas à esfera jurídica extrapatrimonial de quem se relaciona no campo dos serviços culturais em nosso país.

\section{CONSIDERAÇÕES FINAIS}

O estudo buscou revelar pontos de inadequação e de não conformidade constitucional observados na Lei ${ }^{0} 14.046 / 2020$ com o sistema legal vigente. Procurou-se demonstrar que regulações excepcionais e transitórias não devem ser consideradas legítimas quando retiram garantias historicamente asseguradas a sujeitos vulneráveis, ofendendo os valores constitucionais e aumentando o abismo entre os atores das relações de consumo nos contratos de turismo e de cultura.

Reconhece-se que algumas medidas excepcionais podem ser tomadas, mas não pela forma e pela extensão eleita na Lei $\mathrm{n}^{0}$ 
14.046/2020, porquanto na pretensão de proteger o mercado de um colapso econômico, preterem-se os direitos do consumidor naquilo que não tem preço: sua dignidade.

Além de causar embaraços para a restituição dos valores pagos pelos serviços contratados, impondo prazos descabidos para acelerar uma eventual composição - que é apenas conveniente aos fornecedores e aos prestadores - enquanto os consumidores amargam seus próprios colapsos financeiros pela redução de salários e até pela perda de empregos, o texto legal analisado vulnera a dignidade do consumidor ao impossibilitar a reparação por dano moral em qualquer hipótese.

A existência de fontes normativas específicas sobre determinada matéria de consumo não afasta a incidência do CDC. A proteção ao livre mercado é medida salutar para os interesses dos próprios consumidores, entretanto a Lei ${ }^{0}$ 14.046/2020 não pondera adequadamente os interesses contrapostos, realçando a posição de vulnerabilidade do consumidor de tais serviços a partir da limitação excessiva na autonomia de vontade deste. Tudo isso em um claro paradoxo: a medida nasce de uma perspectiva de solidarismo contratual, mas concretamente só cuida da mitigação dos prejuízos do lado dominante na relação negocial.

Data de Submissão: 21/07/2020

Data de Aprovação: 11/02/2021

Processo de Avaliação: double blind peer review

Editor Geral: Jailton Macena de Araújo

Editor de Área: Alana Ramos Araujo

Assistente Editorial: Igor Barbosa Beserra Gonçalves Maciel

\section{REFERÊNCIAS}


CUNHA JUNIOR, Dirley. Curso de Direito Constitucional. 14. ed. Salvador: Juspodium, 2020.

DELGADO, José Augusto. O contrato no Código Civil e a sua função social. In Revista Jurídica. V. 47, n. 263, p. 52-77, set., 1999.

D’AQUINO, Lúcia Souza; MUCELIN, Guilherme. O papel do direito do consumidor para o bem-estar da população brasileira e o enfrentamento à Pandemia de COVID-19. Revista de Direito do Consumidor. vol. 129. ano 29. p. 17-46. São Paulo: Ed. RT, maio-jun./2020

EHRHARDT JUNIOR. Marcos. Revisão Contratual: a busca pelo equilíbrio durante da mudança de circunstâncias. Salvador: Juspodium, 2008.

EHRHARDT JUNIOR. Marcos; COSTA, Eduardo Henrique. A ilegalidade na cobrança de taxa de conveniência por ingressos vendidos na internet: Análise do REsp No 1.737.428/RS. In Revista de Direito do Consumidor. vol. 130. ano 29. p. 515-532. São Paulo: Ed. RT, jul-ago./2020

FERRAZ JUNIOR, Tércio Sampaio. A economia e o controle do Estado. Parecer publicado in O Estado de São Paulo, ed. 4.6.89.

GRAU, Eros Roberto. A Ordem Econômica na Constituição de 1988. 19. ed. São Paulo: Malheiros, 2018.

IRTI, Natalino. L'età della decodificazione. Milano: Giuffrè, 1999.

LÔBO, Paulo. Direito Civil: Parte Geral. Volume 1. 8. ed. São Paulo: Saraiva, 2019.

MARQUES, Claudia Lima. Superação das antinomias pelo diálogo das fontes - $\mathbf{O}$ modelo brasileiro de coexistência entre o Código de Defesa do Consumidor e o Código Civil de 2002. Revista da Escola Superior da Magistratura de Sergipe, Sergipe, n. 7, 2004.

MIRAGEM, Bruno. Curso de Direito do Consumidor. 8. ed. São Paulo: RT, 2019.

MORAES, Maria Celina Bodin. Danos à pessoa humana: uma leitura civil constitucional dos danos morais. Rio de Janeiro: Renovar, 2003.

MORAES, Paulo Valério Dal Pai. Código de Defesa do Consumidor: O princípio da vulnerabilidade no contrato, 
na publicidade, nas demais práticas comerciais. 3. ed. Porto Alegre: Livraria do Advogado, 2009.

OLIVA, Milena Donato. Desafios contemporâneos da proteção do consumidor: codificação e pluralidade de fontes normativas. Revista Brasileira de Direito Civil

- RBDCilvil, Belo Horizonte, v. 16, p. 15-33, abr./jun. 2018.

OLIVA, Milena Donato; TEPEDINO, Gustavo. Fundamentos do Direito Civil - Teoria Geral do Direito Civil, Vol. 1. Grupo GEN, 2020.

RODOTÁ, Stefano. Il dirito de avere diritti. Roma-Bari: Laterza, 2012.

RODOTÁ, Stefano. Quale diritto per il nuovo mondo. En Estudios de derecho civil. Obligaciones y contratos. Libro Homenaje a Fernando Hinestrosa, III, 2003.

SARMENTO, Daniel. Direitos Fundamentais e relações privadas. Rio de Janeiro. Lumen Juris, 2004.

SCHREIBER, Anderson. Direitos da personalidade. $3^{\mathrm{a}}$ ed. São Paulo: Atlas, 2014.

SCHREIBER, Anderson. Devagar com o andor: coronavírus e contratos - Importância da boa-fé e do dever de renegociar antes de cogitar de qualquer medida terminativa ou revisional. Disponível em:

https://www.migalhas.com.br/coluna/migalhascontratuais/322357/devagar-com-o-andor-coronavirus-e-contratosimportancia-da-boa-fe-e-do-dever-de-renegociar-antes-de-cogitarde-qualquer-medida-terminativa-ou-revisional Acesso em 20 jun. 2020.

SCRUTON, Roger. Como ser um conservador. Tradução Bruno Garschagen; Márcia Xavier de Brito.1 ed. Rio de Janeiro: Record, 2015 .

SILVA, Rafael Peteffi da. Caso fortuito ou de força maior: principais delineamentos dogmáticos e conexões com a pandemia do coronavírus. Revista IBERC v. 3, n. 2, p. 220-240, maio/ago. 2020. Disponível em:

https://revistaiberc.responsabilidadecivil.org/iberc/article/view/121 /95 Acesso em 07 ago. 2020.

TARTUCE, Flávio. O coronavírus e os contratos. extinção, revisão e conservação. Disponível em:

http://www.flaviotartuce.adv.br/assets/uploads/artigos/74eb8artigo-flavio-tartuce.docx . Acesso em 20 jun. 2020. 
THEODORO JÚNIOR, Humberto. Direitos do Consumidor. 9. ed. Rio de Janeiro: Forense, 2017.

ZANELLATO, Marco Antonio. Boa-fé objetiva: formas de expressão e aplicações. Revista de Direito do Consumidor. vol. 100. ano 24. p. 141-194. São Paulo: Ed. RT, jul.-ago. 2015. Disponível em: https://revistadedireitodoconsumidor.emnuvens.com.br/rdc/article/ view/29/19. Acesso em 07 out. 2020. 
Consumer Contractual Protection And Law No. 14.046/2020

\author{
Marcos Ehrhardt Júnior
}

Eduardo Henrique Costa

Natália Tenório Fireman Camelo

\begin{abstract}
The article examines Law No. 14,046/2020, which deals with the cancellation, refund and civil liability of services related to the tourism and entertainment industry, and its repercussions on consumer law, from the perspective of dialogue of sources with the Federal Constitution and the Consumer Protection Code. The objective is to investigate whether the treatment conferred by the aforementioned law respects the normative core of the consumer protection microsystem, especially the balance of these contractual relations. The research was carried out based on the deductive scientific method of bibliographic and documentary review in national and foreign doctrine and legislation. It was found that the analyzed legislation brings regression to social achievements in private relations, achieved constitutionally, such as the protection of the vulnerable in conditions of business imbalance. The a priori prohibition of off-balance sheet damages is a clear demonstration of the asymmetry of the legal diploma with the consumer protection system and the full compensation of the damages. Finally, it has been verified that the singularities of each contractual conflict, and possible unfair behavior, should not be disregarded with the limitation imposed by the rule as to the supplier's liability, requiring a case-by-case assessment by the Judiciary.
\end{abstract}

Keywords: Pandemic. Consumer Law. Consumer contracts. Civil liability.

DOI: https://doi.org/10.22478/ufpb.1678-2593.2021v2on43.54080

Conteúdo sob licença Creative Commons: Attribuition-NonCommercial-NoDerivative 4.o International (CC BY-NC-ND 4.0) 